\title{
El método como elemento esencial en el proceso investigador
}

The method as an essential element in the research process

\author{
Alberto L. García García, Universidad Complutense de Madrid \\ Doctor en Comunicación Audiovisual y Publicidad. Profesor del Departamento CAVP1 \\ de la Facultad de Ciencias de la Información de la Universidad Complutense de Madrid. \\ Miembro del Grupo de Investigación COMEIN (Comunicación, Métodos e \\ Innovación). ORCID: https://orcid.org/0000-0002-1268-7431
}

Manuel Sánchez Cid, Universidad Rey Juan Carlos.

Doctor en Comunicación Audiovisual y Publicidad. Profesor en el Departamento de Ciencias de la Comunicación y Sociología de la Facultad de Ciencias de la Comunicación de la Universidad Rey Juan Carlos. Miembro del Grupo de Investigación GISECOM (Grupo Investigador del Sonido Envolvente y la Comunicación). ORCID: https://orcid.org/0000-0002-7683-9000

“El método, es el camino o medio para llegar a un fin, el modo de hacer algo ordenadamente, el modo de obrar y de proceder para alcanzar un objetivo determinado"

Mendieta Alatorre

El estudio y conocimiento de las distintas ciencias conlleva retos que exigen de una planificada determinación en pro de la consecución de los objetivos científicos establecidos, lo que sin duda requiere de métodos efectivos que validen el propio desarrollo de la investigación. Es importante considerar un orden científico abierto a nuevas fórmulas de búsqueda del conocimiento, pero igualmente es necesario e incluso imprescindible el uso de herramientas estructuradas capaces de orientar el camino del saber desde el mismo inicio de la investigación, ya que lo contrario podría provocar giros impropios que, en no pocas ocasiones, provocan ineficacia y confusión conceptual. Y aunque todo proceso investigador suele estar asociado a un orden argumental encaminado a la obtención de resultados contrastables, en demasiadas ocasiones se vincula la intención investigadora a intuiciones no siempre avaladas por un estudio previo basado en el análisis riguroso de las distintas circunstancias que pueden acompañar el devenir de la investigación, lo que suele generar retrasos, desánimo y, en ocasiones, errores conceptuales difícilmente solventables. Es por ello que toda investigación debería ir acompañada de una profunda reflexión previa encaminada al 
establecimiento y conceptualización de un método científico tangible, construido sobre pilares bien fundamentados capaces de afianzar una estructura sólida que determine con claridad todo lo enmarcado en el desafío establecido en la investigación. En otras palabras, un método de investigación eficaz encaminará los procedimientos y ayudará a conseguir los objetivos establecidos.

Por su parte, la consideración de conocimiento científico entraña en sí misma la diversidad de métodos, lo que facilita una multiperspectiva validante a la hora de acotar la definición de los objetivos y la planificación del desarrollo del proceso investigador. Por tanto, resulta interesante destacar que el planteamiento de un método científico, independientemente de su clasificación, debería establecer como principios fundamentales aspectos como: la definición del problema, las respectivas preguntas de investigación, la consecuente hipótesis, el análisis relacional de los problemas y objetivos, así como la identificación del modelo estructural que se va a desarrollar al objeto de la investigación. Esto permite aseverar que los métodos de investigación pueden o deben ser entendidos como instrumentos o conjunto de procedimientos ordenados capaces de orientar la producción científica hacia buen término. No obstante, la elección y definición acertada de un método no significa un éxito definitivo en sí mismo, ya que requiere de una puesta en práctica efectiva y de la valoración solvente de todas las variables que pueden surgir incontroladas en el complejo proceso investigador; proceso que sin duda admite diversas vías a fin de formular una interrelación formal entre los distintos aspectos vinculados a un objeto estudiable.

El método en investigación es, en consecuencia, el elemento estructurador en el que vertebrar el pensamiento originario sobre el que se afrontan las probables soluciones a las cuestiones primigenias planteadas. La Comunicación, articulada como sub-área de conocimiento dentro de las Ciencias Sociales y Humanas, tiene que encontrar su propio hueco estructural con capacidad de articular personalidad científica distinguible, que no separada o aislada, de las Ciencias Sociales.

El reciente Congreso Internacional de Metodologías en Investigación de la Comunicación que, en su sexta edición, se ha celebrado en la Universidad Complutense de Madrid, está consolidando un proceso de racionalización de la metodología específica en y para el ámbito de la Comunicación. Las distintas propuestas de técnicas y metodologías diferentes, de las que este número muestra algunas como referencia, que pudieron ser planteadas y discutidas a lo largo del desarrollo del Congreso, infunden una clara tendencia a tratar de ajustar soluciones a los aspectos específicos del área, a partir de iniciativas fundamentadas en el conocimiento cierto y concienzudo de las metodologías clásicas. La diversidad de temáticas y procedencia de los investigadores participantes en el mismo, indican un relevante y creciente interés en la investigación en Comunicación como instrumento necesario e imprescindible de cohesión social. La Universidad, como entidad necesaria y firme para generar pensamiento crítico, necesita de acciones como este Congreso, germen del presente número de la revista, para explicar y tratar de hacer entender la profunda revolución que la sociedad actual está sufriendo en torno a las diferentes maneras y posibilidades de comunicar.

Y, en todo este maremágnum de ideas y conceptos, la estructuración y jerarquización 
del pensamiento racional debe ser abordado desde la simplicidad y/o complejidad del método científico como base crediticia del conocimiento. En la nueva realidad, construida a partir de certezas, rumores, falacias y sobre-información, es imprescindible generar consensos científicos que permitan asegurar espacios de reflexión fundamentados y libres de todo tipo de prejuicios. Y la metodología es el cimiento del edificio.

Por tanto, el valor implícito aquí asignado al método científico como elemento necesario en todo proceso investigador, se ve reforzado en este segundo número de la Revista Comunicación y Métodos, al aglutinar artículos cuya variada temática encuadrada en diversas especialidades consolida la validez y utilidad de lo aquí reseñado. Se incorporan en el presente número estudios tan diversos como: el análisis de contenido en el proceso de modelización de personajes de ficción; categorías de análisis de la imagen de marca; Benchmarking mediante herramientas TIC; análisis de discurso en influencers para el estudio de la comunicación no verbal; la construcción de la imagen de una ciudad a través de publicaciones de Instagram; optimización de la eficacia del discurso de videojuegos; el impacto de los mensajes de texto de los carteles publicitarios; la experiencia como nuevo horizonte epistemológico y metodológico en la investigación en Comunicación Audiovisual; un modelo de reproducibilidad sonora en musicoterapia pasiva; dificultades de la investigación cualitativa sobre el activismo mediático; métodos múltiples en estudios de comunicación y metodología para el estudio de la historia del videojuego en España, entre otros. Además del interés intrínseco de las distintas aportaciones, esta pluralidad temática ofrece un variado abordaje del proceso científico, mostrando una enriquecedora diversidad que valida la pluralidad de procedimientos a la hora de planificar una investigación. Es por ello, que este segundo número de Comunicación y Métodos, además de agradecer las valiosas aportaciones de todos sus colaboradores, mantiene firme la línea de reconocimiento de todos aquellos procesos de investigación que consolidan su hacer construyendo una estructura investigadora sólida y rigurosa más allá de la mera ornamentación.

HOW TO CITE (APA $\left.6^{\mathrm{a}}\right)$

García-García, A.L., \& Sánchez Cid, M. (2019). El método como elemento esencial en el proceso investigador. Comunicación y Métodos | Communication \& Methods, 1(2), 3-5. doi: $10.35951 / \mathrm{v} 1 \mathrm{i} 1.52$ 